\title{
Calling the Banners: exploring the complex biogeographical history of the Neotropical banner- wing damselflies (Odonata: Polythoridae)
}

Melissa Sanchez Herrera ( $\nabla$ melsanc@gmail.com )

Universidad Del Rosario https://orcid.org/0000-0001-5144-4996

Christopher D Beatty

Cornell University

Renato Nunes

Rutgers The State University of New Jersey

Camilo Salazar

Universidad Del Rosario

Jessica L Ware

Rutgers The State University of New Jersey

Research article

Keywords: biogeographical history of species, New World Tropics, evolution, biogeography, Polythoridae

Posted Date: July 3rd, 2019

DOI: https://doi.org/10.21203/rs.2.11009/v1

License: (9) This work is licensed under a Creative Commons Attribution 4.0 International License.

Read Full License 


\section{Abstract}

Background Sorting out the biogeographical history of species in the New World Tropics is challenging. We here examine the roles of evolution and biogeography in driving the distribution and diversification of the damselflies of the family Polythoridae. This family comprises seven genera with a total of 57 species, distributed across much of Central and South America. Results Through phylogenetic analysis, relaxedclock molecular dating and biogeographical analysis we find these genera originated 56 Ma and started diversifying $\sim 45 \mathrm{Ma}$. As with other neotropical groups, the Polythoridae have a primary origin in the Northern Andes; at least one genus first appears in the Amazon Basin. Diversification rates have been uniform in all genera except one-Polythore-where a significant increase in the late Pliocene ( 3 mya) correlates with mountain building. While our molecular clock suggests correlations with some major geographical events, our biogeographical modeling (with BioGeoBEARS and RASP) found little influence of the formation of the Pebas and Acre systems or Andean mountain building, possibly due to the short branch lengths in our time-dated phylogeny. Conclusion We conclude that this family of damselflies, despite its relatively young age, has developed into genera with diverse distributions and some surprisingly high diversity, despite relatively low habitat diversity. Polythore is a recent radiation where biogeographical events may not be the main drivers of diversification. Other factors like sexual and natural selection acting on color patterns could be involved in generate the extreme diversity in this genus.

\section{Introduction}

Understanding the origins of diversity requires consideration of the many factors that can drive speciation ${ }^{1}$. For groups of species distributed across a large region, geographic isolation may drive diversification, especially if the geographic structure is complex. Other factors, such as ecological diversification (i.e. niche diversification) or sexual selection, are also likely to play a role. In many cases, some, or all, of these factors will come into play, making for a rich, often complicated history to sort out when interpreting modern species relationships.

The New World tropics is a region of amazingly high diversity in a variety of plants and animals, and has a complex history ${ }^{2}$. Shifting continents, multiple instances of mountain building, rivers that change their course, and the expansion and retreat of both freshwater and marine habitats all come together to make a complicated and dynamic foundation on which biological diversity has developed over the last 50 million years (Ma). These include the uplift of the different regions of the Andes, as well as the Venezuelan Highlands, the formation of the extensive Amazonian floodbasin in the Miocene (Pre-Pebas, Pebas and Acre), the further development of the Amazon and Orinoco drainages, the dry/wet climate cycles of the Pliocene/Pleistocene, and the formation of the Panamanian Land Bridge between the Tumbes-Chocó-Magdalena regions and Central America ${ }^{3} .4$

In a number of groups (tropical frogs ${ }^{5,6}$, butterflies ${ }^{7}$, lupines ${ }^{8}$, birds ${ }^{9}$ ) this changing geography has driven substantial-sometimes rapid-diversification, but not always in the same way. The diversification 
driven by these geographic changes often promotes niche diversification, with species taking advantage of the distinct ecological niches found in each local environment. This leads to adaptive speciation ${ }^{10}$, further increasing diversity beyond the form of the landscape. Here we investigate the origins of diversity in the banner-winged damselflies (Polythoridae), a group that is distributed across much of Central and South America.

Polythoridae comprises 57 species across seven genera (Chalcopteryx Selys, Chalcothore De Marmels, Cora Selys, Euthore Selys, Miocora Calvert, Polythore Calvert and Stenocora Kennedy) that differ markedly in their distribution: some are found widely across the continent, while others are limited to a single country or region. While damselflies as a group are generalist predators in both their larval and adult forms, the types of aquatic habitats in which their odonate larvae are found vary, with some species using lakes and ponds, while others inhabit streams and rivers. The larvae of Polythoridae prefer moving water; most species are found in small streams in mountain regions, though some additionally exist within slow streams in the Amazon Basin ${ }^{11}$. These species display a diverse range of colors and patterns on both the wing and body within and among genera; previous work by Sánchez Herrera et al. ${ }^{12,13}$ has shown that for some genera, wing colors may be polymorphic, raising the question of what factors drive this color diversity.

We explore hypotheses concerning the diversity within Polythoridae, investigating the influence of the changing biogeography on this family, and its ability to explain the distribution and phylogenetic relationships we see today. Using relaxed-clock molecular methods we estimate divergence times within and among the genera of this family. We also investigate their biogeographical patterns of diversification in relation to the mountain building events of the Andes, as well as the extent of marine and freshwater environment incursions in different periods that might have influenced distribution and speciation in these genera. Specifically, we evaluated the following questions: (1) Have the Andes and/or the Amazon Basin acted as the centers of origin and diversification of the family Polythoridae? (2) Are there multiple interchanges among Neotropical regions, particularly between Amazon and Andean regions and the Andean and Central America? (3) How has Polythoridae diversified (e.g. constant, episodic) through evolutionary time? (4) Are there significant diversification shifts associated with these biogeographical events that can indicate an adaptive radiation for the genera within the family? Overall, this work represents the first continental-scale biogeographical analysis of a neotropical family of damselflies. With their reliance on aquatic habitats, damselflies are likely to respond very differently to the landscape than plants, vertebrates, or terrestrial insects; our analysis allows us to consider the formation of diversity in the modern neotropics through an unexplored perspective.

\section{Results}

\section{Phylogeny and Time Divergence}


Our phylogenetic reconstruction was generally consistent with the clades previously recovered by Sánchez Herrera et al. ${ }^{13}$ (Fig 1), though our current dataset includes twelve additional species. The family Polythoridae separated from our Outgroups 56 Ma (70 - $48 \mathrm{Ma} 95 \% \mathrm{Cl}$ [confidence intervals], pp [posterior probability] = 1). Our time divergence reconstruction suggests that the family Polythoridae began to diverge $~ 42 \mathrm{Ma}(48-35.11 \mathrm{Ma} 95 \% \mathrm{Cl}, \mathrm{pp}=0.992)$ with the emergence of the Chalcopteryx clade during the mid-Eocene epoch. The Chalcopteryx clade (i.e. Chalcapteryx and Chalcothore) itself began to diversify later, $24 \mathrm{Ma}(35.7-12.52 \mathrm{Ma} 95 \% \mathrm{Cl}, \mathrm{pp}=0.999)$, while all the other Polythoridae taxa (Cora s.s., Miocora, Euthore and Polythore clades) begin to diversify $33.14 \mathrm{Ma}(41.52-25.52 \mathrm{Ma} 95 \% \mathrm{Cl}$, $\mathrm{pp}=1)$. Chalcothore separated from Chalcopteryx $\sim 23.49 \mathrm{Ma}(35.73-12.51 \mathrm{Ma} 95 \% \mathrm{Cl}, \mathrm{pp}=0.999)$ during the late Oligocene and early Miocene boundary, however the genus Chalcopteryx only diversified during the late Miocene 9.62 Ma (16.97 - 4.325 Ma 95\% Cl, $\mathrm{pp}=0.997)$. The Cora s.s clade separates from all the other taxa $\sim 33.14 \mathrm{Ma}$, however its diversification estimates to be $\sim 17 \mathrm{Ma}(24.24-9.06 \mathrm{Ma}, \mathrm{pp}=1)$ around the end of the early-Miocene (Fig 1). The Miocora clade diversification took place 14.5 Ma (22.5 - $6.78 \mathrm{Ma}, \mathrm{pp}=1$ ), a few million years after Cora s.s during the mid-Miocene, although it separates from the Euthore and Polythore clade 24.75 Ma $(32.18-17.28 \mathrm{Ma} 95 \% \mathrm{Cl}, \mathrm{pp}=1)$ during the late-Oligocene or early Miocene epochs (Fig 1). The two sister clades of Euthore and Polythore diverged from each other around the same epoch as Miocora, 22.28 Ma (29.37 - 15.70 Ma, pp = 1), but both start their diversification concurrently around the early Miocene, though Euthore estimates are slightly older than those for Polythore (Fig 1). Euthore diversified $\sim 18.39 \mathrm{Ma}(25.06-12.17 \mathrm{Ma}, \mathrm{pp}=1$ ) while Polythore seems to be $\sim 16.68 \mathrm{Ma}(22.80-10.46 \mathrm{Ma}, \mathrm{pp}=1)$. Within the Euthore clade we recovered two sister clades: Euthore sensu stricto (e.i. E. fasciata fasciata, E. fasciata fastigiata, E. fasciata plagiata, E. fassli, E. sp. nov), and what used to be part of Cora (i.e. E. lugubris and E. klenei). Within the Euthore cladethe diversification times recovered suggest that Euthore sensu stricto, $6.62 \mathrm{Ma}(10.72-3.09 \mathrm{Ma}, \mathrm{pp}=1)$, is significantly younger that the previous classified Cora species within this clade, $\sim 12.8 \mathrm{Ma}$ (19.04 - 6.13 $\mathrm{Ma}, \mathrm{pp}=0.978)$.

In the highly speciose Polythore clade we recovered the diversification times for all the previous geographical clades reported in Sanchez Herrera et al. ${ }^{13}$ (see color codes in Fig 1). The Amazonian clade diversified $\sim 8.72 \mathrm{Ma}(14.36-3.24 \mathrm{Ma} 95 \% \mathrm{Cl}, \mathrm{pp}=1)$, while the Andean clade was $\sim 10.57 \mathrm{Ma}$ (15.43 $6.41 \mathrm{Ma} 95 \% \mathrm{Cl}, \mathrm{pp}=1)$. Within the Andean clade, the West and East Andean clades diversified $\sim 2.98 \mathrm{Ma}$ (5.34 - 1.19 Ma 95\% Cl, $\mathrm{pp}=1)$ and $~ 7.16 \mathrm{Ma}(10.78-4.18 \mathrm{Ma} 95 \% \mathrm{Cl}, \mathrm{pp}=1)$, respectively. Moreover, the diversification estimates for the North ( 4.21 Ma, $6.35-2.35 \mathrm{Ma} 95 \% \mathrm{Cl}, \mathrm{pp}=1)$ and South Eastern ( 3.25 Ma, 5.57 - 1.64 Ma 95\% Cl, $\mathrm{pp}=1$ ) clades suggest it occurred around the Pliocene - Pleistocene epochs (Fig 1). Our lineage through time plot suggest that the major accumulation of lineages for Polythoridae occurred during the Miocene epoch (Fig 1). Our lineage through time plot also shows that most of the species diversity within the family was acquired during the later Miocene, Pliocene and Pleistocene epochs (Fig 1).

\section{Biogeographical Reconstruction}


For the three scenarios (Control, P\&AS, and ANDES) we evaluated, the best biogeographical model selected by BioGeoBEARS was DEC+J and the least fitted was the BayArea model (corrected Akaike Information Criterion (AICC) values $>245$, Supplementary Table 1). However, following the Ree and Sanmartín ${ }^{14}$ critique of the DEC+J model, we also reconstructed the next best fitted biogeographic model based on the AICc, using both BioGeoBEARS and RASP, for all the scenarios (Table 1). Comparing across the different BioGeoBEARS and RASP reconstructions there were no major differences among our three scenarios, however we found several disparities among the ancestral area estimation performed by BioGeoBEARS and RASP within each scenario (first row in Table 1).

For all scenarios, internal nodes seem to be the most consistent across the biogeographical models (i.e. nodes $78,79,80,8$; Fig 2), however the most likely areas detected for the major genera clades were not consistent across the BioGeoBEARs and RASP approximations in all the scenarios (Control, P\&AS and ANDES). The Chalcopteryx clade showed the following pattern: the BioGeoBEARs models (DEC+J, DIVALIKE, DEC) suggest the Northwest (C) and Northeast (D) Andes are the ancestral areas, while for the RASP reconstructions (S-DIVA, S-DEC) more plausible areas are the Amazon Basin (G), the Venezuelan Highlands (E) and the Brazilian Shield (I) (Fig. 2, Table 1). The Cora s.s. clade highlighted a similar issue across scenarios; here the BioGeoBEARs models consistently support the Northwest Andes (C) as an ancestral area, although depending on the model (Fig. 2, Table 1) it can be accompanied by the Northeast Andes (D) and/or the Amazon Basin (G) and the Venezuela Highlands (E). For the RASP reconstructions of Cora s.s., the Northwest Andes (C) again is the most commonly predicted ancestral area, followed by the Northeast Andes (D) and/or the Central Andes (F). For the Miocora, Euthore s.I. and Polythore clades specifically, the BioGeoBEARs DIVALIKE model showed the greatest inconsistency in comparison with the other models (Fig. 2, Table 1). For Miocora, DEC+J suggests the Northwest Andes (C), while DIVALIKE suggests as ancestral areas the Northeast Andes (D), Central Andes (F) and Amazon Basin (G); the RASP models consistently support the Northwest Andes (C) and the Tumbes-Chocó-Magdalena Valley (B). For Euthore s.I. DEC+J again suggests the Northwest Andes (C), while DIVALIKE supports the Central Andes (F), Guiana Shield (H) and Brazilian Shield (I); in contrast the RASP S-DIVA models support the Northwest (C) Andes (Fig. 3). Finally, for Polythore DEC+J suggests either the Northwest Andes (C) or the Northeast Andes (D) and Central Andes (F) as ancestral areas, while DIVALIKE suggests the Northeast Andes (C) and the Tumbes-Chocó-Magdalena Valley (B); the RASP models concur in the Northwest (C), Northeast (D) Andes and the Amazon Basin (G) (Fig. 2, Table 1). It is interesting to note that the different scenarios (Control, P\&AS, ANDES) within our BioGeoBEARS and RASP analyses, which accounted for many of the major geographical events in South America over the last 50 million years, did not produce fundamentally different results; inclusion of the formation of the Pebas and Acre wetlands systems, as well as mountain building events, did not alter our results in comparison with a simple control scenario that allowed free dispersal between adjoining regions. This may be due to the relatively short branch lengths within the tree for most of the species groups, especially within Polythore. Conversely, any long branch lengths within the tree may also suggest the potential for undetected extinction events early in the formation of some of these genera. Our S-DEC model implemented in RASP suggest several dispersal (29), vicariance (10) and extinction (3) events within the different genera of Polythoridae (Supplementary Figure S2); many of 
these involve movement within and between the different ranges of the Andes, as well as movement into the Amazon, Guiana Shield, Venezuela Highlands, the Tumbes-Chocó-Magdalena Valley, and Central America.

\section{Diversification Analyses}

The Episodic Birth-Death with multiple time periods was the best model explaining the diversification pattern in this group of damselflies (Table 2). The estimated net diversification $(\lambda-\mu)$ and speciation $(\lambda)$ rates show an increase, however the relative extinction $(\lambda / \mu)$ and extinction $(\mu)$ rates pattern seem to behave constantly through time (See Supplementary Figure S3). The Branch specific model detected a shift in diversification $(\lambda-\mu)$ rate corresponding to the Andean Clade in Polythore with the highest shift in the Eastern Clade (Fig 3). When we observed the relative extinction $(\lambda / \mu)$ rate across the tree, we observed that this rate also decreases for this clade (Fig 3). Our estimates show that the other clades within this family have a more constant diversification $(\lambda-\mu)$ and relative extinction $(\lambda / \mu)$ rates across the branches of the estimated tree.

\section{Discussion}

Overall, our results suggest that Polythoridae originated around the Eocene, however most of the diversification within the family appeared during the Miocene, Pliocene and Pleistocene epochs (Fig 1). During these periods there were a number of major biogeographical events occurring, including the uplift of different regions of the Andes, as well as the formation of the Pebas and Acre Systems. Our biogeographical analyses suggest strong support for an origin-or at least early diversification-in the Northeastern and Northwestern Andes for most genera in Polythoridae. Chalcopteryx clade, the earliest of the modern genera to emerge in our tree, may have had an Amazonian origin (Fig 2, Supplementary Figure S4). Chalcoptery $x$ clade separated during the marine condition retreat period in South America $42 \mathrm{Ma}$; this basal node is consistent with recent studies that suggest Amazonia as the primary source of Neotropical diversity ${ }^{15}$. Cora sensu stricto has an origin in the Northeastern and Northwestern Andes (Supplementary Figure S4) during the period when the sub-Andean river system was forming; Miocora appears later in this period with an origin in the Northwestern Andes (Supplementary Figure S4). Euthore and Polythore separate in the early Pre-Pebas, with Euthore in the Northeastern Andes (Supplementary Figure S4), and Polythore in the Northeastern and Northwestern Andes, as well as the Amazon (Supplementary Figure S4). This potential for an Amazonian origin in Polythore is likely driven by a basal clade of the genus, containing Polythore aurora, and $P$. mutata, which is currently found in the Amazon. These arose as a separate lineage in the mid-Miocene, not long after the estimated formation of the Pebas System. The other Amazonian Polythore (P. manua and P. spaeteri) appear to have evolved very recently, in the mid-Pleistocene, and are found within the Amazon Basin relatively near the Andes; they emerge from within a clade found mainly in the Central Andes. Taken as a whole an origin in the Northern Andes, with a subsequent distribution to the Amazon and Central Andes, seems the most likely scenario for Polythore. 
An origin in the Northern Andes is consistent with the analysis of several other neotropical groups, which suggests that mountain building in these regions was an important impetus generally for neotropical diversity ${ }^{9,16}$. This appears to also be the case with Polythoridae, as the genera not only have estimated ancestral areas associated with the Andes, but the timing of origination and diversification also coincides with periods of Andean uplift (Fig 2). Diversification in many of the genera of Polythoridae took place much later than their origin within the tree, leading to long branch lengths at the base of the tree, and many very short branches near the tips. While Chalcopteryx originates during the period or marine retreat, diversification in this group doesn't take place until the development of the Acre system. Likewise, Euthore, with its origin during the early Pre-Pebas, does not begin to diversify until the late Pre-Pebas. Cora, Miocora and Polythore diversify during the Acre, with most diversity in Polythore developing during the Modern River System era, much of it during the Pleistocene (Fig 2). Many of these later periods of diversification are also associated with periods of intensified Andean uplift, despite our biogeographical modeling not finding definitive support for an Andean influence on species diversity (Fig 2, Supplementary Figure S5).

Our analyses suggest that Polythoridae has been diversifying through an episodic pattern (Table 2). Speciation $(\lambda)$ and net diversification $(\lambda-\mu)$ show an overall increase through time, while relative extinction $(\lambda / \mu)$ and extinction $(\mu)$ rates seem to remain somewhat constant through their evolutionary history. However, our branch-specific model of diversification shows a significant shift for the Andean Clade within the genus Polythore which might suggest that at least for this genus the intensified Andean uplift during the Pliocene has been promoting speciation (Fig 3). Genera such as Stenocora (not included in this analysis) and Chalcothore have relatively limited distributions, while Chalcopteryx, Cora, Miocora, Euthore and Polythore are found broadly across different regions in Central and South America. This may be somewhat tied to species diversity within these genera: for example, Polythore and Euthore are species rich (21 and 14 species, respectively) while Chalcothore and Stenocora are each represented by a single species. Still, species richness does not immediately explain the distribution range of all these genera; Chalcopteryx, with a broad distribution across much of South America, comprises 5 species, while Cora s.s, with its habitat similarities to Polythore and Euthore, has only 9 species.

For much of the family Polythoridae, vicariance and dispersal, with species moving into new habitats as they become available, is a likely explanation for the current patterns of diversity. We found multiple interchanges among the Amazon and Andean regions; many of them involved movement within and between the different ranges of the Andes, as well as movement into the Amazon, Guiana Shield, Venezuela Highlands, the Tumbes-Chocó-Magdalena Valley, and Central America. As noted above, Chalcopteryx may have originated in the Amazonian region and diversified through vicariance during the formation of the Acre System. Polythore shows a likely pattern of dispersal from the Andean regions to the Amazon in some clades, as well as movement from the Northern to Central Andes. As observed above, a basal node comprised of a Polythore clade dispersed early to the Amazon, while speciation into the Amazon from the Central Andes occurred more recently. Nodes separating the Northwestern Andean from Northeastern/Central Andean species likely represent a case of vicariance, as does the separating of 
the Amazonian clade. Some extinction is predicted to have been associated with the 'picta' node in Polythore (Supplementary Figure S2). On the other hand, Euthore moved from the Northwestern to Northeastern Andes and then to the Venezuelan highlands. This genus is currently found at locations from 1000-2000 meters in elevation; it is plausible that they colonized new habitats that became available during mountain building events in the Andes and Venezuelan highlands. There is also some likelihood of extinction in the Euthore 'proper' node. Cora s.s and Miocora diversification was more likely driven by dispersal, as it covers a range of landscape types, and has moved across the Isthmus of Panama, the only group in Polythoridae to do so. Interestingly, the age at which both of these genera diversified matches the age suggested by recent geological studies of the Central American Seaway closure during the middle of the Miocene ${ }^{3}$.

Beyond physical isolation, are there other factors likely involved in the diversification in these groups during the Andean uplift? In groups such as plants, the changing conditions as elevational gradients develop have created ecotones along which species have diversified ${ }^{8,17}$. In butterflies, the changing range of host plants in response to gradients, and shifts to new hosts plants in parallel with these changes, have driven diversity ${ }^{7,18}$. For the damselflies of Polythoridae, habitat specialization is less obvious. Chalcopteryx are found mainly in lowland and Amazonian stream habitats for example, while other groups, such as Euthore, are found at higher elevations. Within Polythore we see one distinct Amazonian clade, while the majority of the remaining species are found at higher elevations throughout the Andes. As organisms with an obligate aquatic life stage, the streams used by these damselflies do not appear to differ greatly at different elevations. The assemblage of prey available may be different in and around these streams, but as generalist predators odonates are able to take advantage of whatever prey may be available, as long as it is in sufficient abundance.

The most outstanding group within the Polythoridae from a diversity standpoint is the Andean Clade of Polythore (Fig 1). What might be driving the increase in Andean Polythore diversity? While all these species have relatively similar habitat requirements, they have generally disjunct distributions within the Andes, such that any local stream normally hosts only a single Polythore species, sometimes two species. The wing color diversity characteristic of Polythore is highest within these groups--the central Andean Polythore have wings that include bands of black, orange and yellow patterns, while those of the Northeastern Andes have intense black and white patterning (except for $P$. concinna, which is orange). This color diversity also appears to be polymorphic within some of these clades ${ }^{12,13}$; do this color diversity represent an adaptive radiation within Polythore? Some of the color diversity could be explained by sexual selection, with local mate choices driving diverse color patterns in different regions ${ }^{19,20}$. Likewise, wing color may be under other constraints, such as thermal tolerance or selection by predators 21 . Having robust phylogenetic hypotheses will allow for further exploration of the reasons behind this radiation in Polythore, where population-level analysis will be a likely next step to disentangling the complex history of these striking creatures.

\section{Methods}




\section{Taxon Sampling}

A total of forty-eight of the 57 species of Polythoridae were included for all reconstructions presented here. All the taxa from Sanchez et al. 2018, including outgroups of other related Calopterygoid taxa (Philogangidae, Euphaeidae, and Pseudolestidae), are included within the analyses, with an additional 12 polythorid species new to these analyses. Geographic origin, collector details, and Genbank Accession Numbers for all specimens are summarized in Supplementary Table S6.

\section{DNA amplification, sequencing, and alignment}

For the 12 species new to this analysis we extracted DNA from either the legs or $1 / 4$ of the pterothorax using a DNeasy Tissue Kit (QIAGEN) from each specimen following the manufacturer's protocol. We amplified three mitochondrial and four nuclear fragments: Cytochrome Oxidase I ( 799bp), NAD dehydrogenase ( 548 bp), 16S, ( 340bp), Elongation Factor ( 900 bp), 28S ( 340bp) and 18S ( 600bp) (see Supplementary Table S7 for a list of primers used). All gene fragments were amplified using PCR conditions as described in the associated publications for each pair of primers (Supplementary Table S7) Macrogen USA Inc. laboratories (NY) performed the purification protocol for the PCR products $(15 \mu \mathrm{l}$ final volume for each primer) and the Sanger DNA sequencing. Primer contig assembly, peak chromatogram verification and the generation of per-individual consensus sequences were done using Geneious v 822 . All fragments were aligned using MAFFT ${ }^{23}$ and then manually aligned in Mesquite ${ }^{24}$. Ribosomal genes were aligned manually with reference to secondary structure using the methods described in Kjer ${ }^{25}$ and Kjer et al. ${ }^{26}$. Finally, all genes were concatenated using Mesquite for the overall analyses.

\section{Time Divergence Analysis}

A relaxed-clock molecular dating analysis on the partitioned dataset was run using BEAST v 1.8.4 ${ }^{27}$. Specifically, we partitioned the gene fragments as follows: (i) We linked the sites and clock models for all mtDNA fragments and (ii) unlinked all nuclear ones from their clock and site models. We implemented the appropriate model selection for each partition: HKY + G4 for all mtDNA, JC for 18S and PMRT, 28S and for EF1 we set the model to GTR + G, models obtained using the model selection tool of IQTree ${ }^{28}$. We used lognormal relaxed clock models for all partitions, under a Yule speciation model. We generated a best ML phylogram with proportional branch lengths using the appropriate partition models using IQTree 28 as the starting tree for the analysis. Table 3 shows the calibrated nodes (4), stem fossils (10) and prior distributions selected for the analyses. We ran four independent analyses to ensure convergence of the MCMC; convergence was checked using Tracer $1.7^{29}$. Finally, the independent runs for each treatment were combined using LogCombiner v 1.8.3 ${ }^{27}$. The dated ultrametric tree was obtained using TreeAnnotator v 1.8.3 ${ }^{27}$ and visualized using Figtree v 1.4 (http://tree.bio.ed.ac.uk/software/figtree/) and 
the $\mathrm{R}$ package ggtree ${ }^{30}$. With the best ultrametric tree we obtain a lineage through time plot using the $\mathrm{R}$ package APE ${ }^{31}$.

\section{Biogeographical Reconstructions}

The ancestral range estimation was performed with the following software: R package Biogeobears v.0.2.1 ${ }^{32}$ and RASP (Reconstruct Ancestral State in Phylogenies) ${ }^{33}$. Both software packages allowed us to customize dispersal rates matrices and time stratification events, as well as infer areas among the following historical biogeography frameworks: Dispersal-Vicariance Analysis (DIVA ${ }^{34}$ ), Statistical Dispersal-Vicariance (S-DIVA ${ }^{35}$ ), Dispersal-Extinction Cladogenesis (DEC ${ }^{36}$ ), and Bayesian inference of historical biogeography for discrete areas (BayArea ${ }^{37}$ ). In addition, Matzke ${ }^{38}$ included a new parameter in all the models accounting for what he calls the founder-event speciation. These are described as "jumping dispersal events $(\mathrm{J})$ ", which are rare events that occur when a new population colonizes a new area ${ }^{38}$. In particular, BioGeoBEARS has implemented model selection among six different historical biogeographic scenarios (DEC, DEC+J, DIVALIKE, DIVALIKE $+\mathrm{J}$, BayArea, BayArea $+\mathrm{J} ;{ }^{32}$ ). Although, Ree and Sanmartín ${ }^{14}$ recently highlighted there are conceptual and statistical issues with the DEC $+\mathrm{J}$ model implemented in BioGeoBEARS, which can sometimes favour unparsimonious numbers for "jumping dispersal events"; and as a result it will not reflect a more close approximation of the "true" model of range evolution. For our analyses, we designated nine distinct geological areas based on the geological literature ${ }^{2,3,39}$, which include; (A) Central America, (B) Tumbes-Choco-Magdalena, (C) North Western Andes, (D) North Eastern Andes, (E) Venezuela Highlands, (F) Central Andes, (G) Amazon Basin, (H) Guiana Shield, and (I) Brazilian Shield (See Figure 2, S4). The extant species distributions for each of our species at the tips of our time calibrated tree (Fig 2) were compiled from our locality data, and specimen records information from the following collections: Florida State Arthropod Collection (FSCA), U.S National Entomological Collection (USNM), Andes Museum of Natural History (ANDES), Entomological Collection of the Universidad de Antioquia, Colombia (CEUA), and the Rutgers Newark Entomological Collection (RUN_ODO). Ranges were restricted to be comprised of at most three different areas as there are no extant species that occupy a range made up of more than three of the determined areas. Impossible adjacency range combinations were manually removed from the ranges list used by BioGeoBEARS during the inference of ancestral states. We designed and tested three different scenarios; Control, P\&AS and ANDES, to reconstruct the biogeographical history of Polythoridae. For the control scenario, our hypothesis was that their geological events including the Andes uplift and Marine incursions of South America did not play an important role in the dispersal and diversification of the family Polythoridae. While for scenarios P\&AS and ANDES, the latter geological events played a role in the dispersal and diversification of this family. In particular, scenario P\&AS tested only the geological events in South America including marine incursion and Pebas/Acre systems; while the scenario ANDES accounts for the gradual uplift of the Andes Cordillera. Details on the model parameters, areas allowed, dispersal probabilities and time stratification schemes for each of these scenarios are explain in the Supplementary Appendix S8. Each of these scenarios were subject to the six available historical 
biogeographic models of BioGeoBEARS, from the best-fit model based on the corrected Akaike Information Criterion (AICC) weights. However following the recommendations of Ree and Sanmartín ${ }^{14}$ we assessed model consistency by comparing among the selected BioGeoBEARS models and carefully examined the reconstructions performed for those models in both BioGeoBEARS and RASP. Afterwards, we favored the model based on best fit for the empirical information on Polythoridae and method consistency. The best selected reconstructed areas models, for each scenario were mapped over the best time calibrated phylogeny and the directionality of the dispersal and vicariance events was represented using maps for each major clade. ${ }^{32,38}$

\section{Time Diversification Analyses}

To investigate the patterns of diversification and extinction rate variation through time and across lineages, we chose RevBayes ${ }^{40,41}$ to test the best diversification models and rate shifts, due to the high uncertainty associated with phylogenetic tree estimation. We calculated the Bayes Factors ${ }^{42}$ for each pair of candidate models estimating the marginal Likelihood $(\mathrm{mlnL})$ using two sampling algorithms (stepping-stone sampling ${ }^{43}$ and path-sampling ${ }^{44}$ ) among the following models: Yule Pure-Birth Model, Birth-Death Constant Model and Episodic Birth-Death Models with multiple time intervals (4, 10 and 100 $\left.{ }^{45}\right)$. Once the best model through time was selected we calculated the speciation $(\lambda)$, extinction $(\mu)$, net diversification $(\lambda-\mu)$ and relative extinction $(\lambda / \mu)$ for the best model; all plots were generated using the RevGadgets package in $\mathrm{R}^{40}$. In addition, we used the Branch Specific Diversification Model implemented

in RevBayes ${ }^{40,46}$ to detect rate shifts across lineages. For all the models implemented in RevBayes ${ }^{40}$ we assumed a uniform taxon sampling and an incomplete sampling fraction of $48 / 57$. For the model selection, we ran a total of $5000 \mathrm{MCMC}$ generations with a burnin of 1000 generations, all the parameter outputs were checked in Tracer ${ }^{29}$ to assess the ESS, prior and posterior probability, and markov chain proper behavior. We estimated the $\mathrm{mlnL}$ of the models sampling the power posterior of each model for 1000 MCMC generations with a burnin of $10 \%$. For the branch specific estimation, we assumed the heterogeneous model and we test several rate categories ( $\mathrm{N}=1$ (constant), 4 and 10 ) across the lineages, for each rate we obtained the marginal probabilities and Bayes Factors as explained above. For the best selected model, we wrote a file with all the estimated parameters ( $\lambda$ avg, $\mu$ avg, $\lambda-\mu$ avg, $\lambda / \mu$ avg and its $95 \%$ confidence ranges) for each branch that can be mapped over our BEAST time divergence tree and was visualized using FigTree (http://tree.bio.ed.ac.uk/software/figtree/).

\section{Declarations}

\section{ACKNOWLEDGEMENTS}

We are grateful to Adolfo Cordero, Joachim Hoffman, Juan Grados, Andrea Encalada for their support during fieldwork collection and permit solicitation. Special thanks to the Tiputini Research Station, Los Cedros Reserve, Pampa Hermosa Lodge for their hospitality. To Emilio Realpe, Cornelio Bota, Rosser 
Garrison, Natalia von Ellenrieder, Bill Mauffray and Ken Tennessen for allowing access to their personal collections, the Florida State Arthropod Collection, Museo ANDES, Universidad de Antioquia Entomology Collection. We would also like to give a special thank you to the following Rutgers-Newark undergraduate students who helped with the molecular bench work: Daniel Troast, Gabby Hanna, Meriem Hanna, Adriana Morocho and Nevin Mathews. We acknowledge the Ministerio de Agricultura de Peru, Ministerio de Medio Ambiente de Colombia and Ecuador for allowing the specimen collection. Funding for this work was provided in part through the National Geographic Society Waitt Explorer Grant W265-13 awarded to MS, JW by startup funds through Rutgers-Newark, CS and MS by the Patrimonio Fondo Nacional de Financiamiento para la Ciencia, Tecnología y la Innovación Francisco José de Caldas (COLCIENCIAS) number FP448442-072-2016, ER and MS by the Proyecto de Ordenamiento Profesoral from the Universidad de los Andes.

\section{Author Contributions:}

MSH performed field collection, lab work and analysis and drafted the manuscript. CDB performed field collection and manuscript drafting. RN performed analysis and drafted components of the manuscript. CS and JW contributed to manuscript preparation.

Competing interests

The author(s) declare no competing interests.

\section{Data Availability}

Data are available in GenBank; see Supplementary Table S6 for accession numbers.

\section{References}

1. Morrone J. Evolutionary Biogeography: An Integrative Approach with Case Studies. Columbia University Press; 2009.

2. Hoorn C, Wesselingh FP, ter Steege H, Bermudez MA, Mora A, Sevink J, et al. Amazonia through time: Andean uplift, climate change, landscape evolution, and biodiversity. Science. 2010;330:927-31.

3. Montes C, Cardona A, Jaramillo C, Pardo A, Silva JC, Valencia V, et al. Middle Miocene closure of the Central American Seaway. Science. 2015;348:226-9.

4. Potter PE, Szatmari P. Global Miocene tectonics and the modern world. Earth-Sci Rev. 2009;96:279-95.

5. Santos JC, Coloma LA, Summers K, Caldwell JP, Ree R, Cannatella DC. Amazonian amphibian diversity is primarily derived from late Miocene Andean lineages. PLoS Biol. 2009;7:e56. 
6. Castroviejo-Fisher S, Guayasamin JM, Gonzalez-Voyer A, Vilà C. Neotropical diversification seen through glassfrogs. J Biogeogr. 2014;41:66-80.

7. Lisa De-Silva D, Mota LL, Chazot N, Mallarino R, Silva-Brandão KL, Piñerez LMG, et al. North Andean origin and diversification of the largest ithomiine butterfly genus. Sci Rep. 2017;7:45966.

8. Contreras-Ortiz N, Atchison GW, Hughes CE, Madriňán S. Convergent evolution of high elevation plant growth forms and geographically structured variation in Andean Lupinus (Fabaceae). Bot J Linn Soc. 2018;187:118-36.

9. Hazzi NA, Moreno JS, Ortiz-Movliav C, Palacio RD. Biogeographic regions and events of isolation and diversification of the endemic biota of the tropical Andes. Proc Natl Acad Sci U S A. 2018;115:7985-90.

10. Weissing FJ, Edelaar P, van Doorn GS. Adaptive speciation theory: a conceptual review. Behav Ecol Sociobiol. 2011;65:461-80.

11. Garrison RW, von Ellenrieder N, Louton JA. Damselfly Genera of the New World: An Illustrated and Annotated Key to the Zygoptera. Johns Hopkins University Press; 2010.

12. Sánchez Herrera M, Kuhn WR, Lorenzo-Carballa MO, Harding KM, Ankrom N, Sherratt TN, et al. Mixed signals? Morphological and molecular evidence suggest a color polymorphism in some neotropical polythore damselflies. PLoS One. 2015;10:e0125074.

13. Sanchez Herrera M, Beatty C, Nunes R, Realpe E, Salazar C, Ware JL. A molecular systematic analysis of the Neotropical banner winged damselflies (Polythoridae: Odonata): Phylogenetic relationships of Polythoridae. Syst Entomol. 2018;43:56-67.

14. Ree RH, Sanmartín I. Conceptual and statistical problems with the DEC+J model of founder-event speciation and its comparison with DEC via model selection. J Biogeogr. 2018;45:741-9.

15. Antonelli A, Zizka A, Carvalho FA, Scharn R, Bacon CD, Silvestro D, et al. Amazonia is the primary source of Neotropical biodiversity. Proc Natl Acad Sci U S A. 2018;115:6034-9.

16. Antonelli A, Daniel Kissling W, Flantua SGA, Bermúdez MA, Mulch A, Muellner-Riehl AN, et al. Geological and climatic influences on mountain biodiversity. Nat Geosci. 2018;11:718.

17. Bacon CD, Velásquez-Puentes FJ, Hoorn C, Antonelli A. Iriarteeae palms tracked the uplift of Andean Cordilleras. J Biogeogr. 2018;45:1653-63.

18. Chazot N, De-Silva DL, Willmott KR, Freitas AVL, Lamas G, Mallet J, et al. Contrasting patterns of Andean diversification among three diverse clades of Neotropical clearwing butterflies. Ecol Evol. 2018;8:3965-82. 
19. Kronforst MR, Young LG, Kapan DD, McNeely C, O’Neill RJ, Gilbert LE. Linkage of butterfly mate preference and wing color preference cue at the genomic location of wingless. Proc Natl Acad Sci U S A. 2006;103:6575-80.

20. Cooper IA. Ecology of sexual dimorphism and clinal variation of coloration in a damselfly. Am Nat. 2010;176:566-72.

21. Moore MP, Lis C, Gherghel I, Martin RA. Temperature shapes the costs, benefits and geographic diversification of sexual coloration in a dragonfly. Ecol Lett. 2019;22:437-46.

22. Kearse M, Moir R, Wilson A, Stones-Havas S, Cheung M, Sturrock S, et al. Geneious Basic: an integrated and extendable desktop software platform for the organization and analysis of sequence data. Bioinformatics. 2012;28:1647-9.

23. Katoh K, Standley DM. MAFFT multiple sequence alignment software version 7: improvements in performance and usability. Mol Biol Evol. 2013;30:772-80.

24. Maddison WP, Maddison DR. Mesquite: a modular system for evolutionary analysis. 2018. http://mesquiteproject.org .

25. Kjer KM. Use of rRNA secondary structure in phylogenetic studies to identify homologous positions: an example of alignment and data presentation from the frogs. Mol Phylogenet Evol. 1995;4:314-30.

26. Kjer KM, Honeycutt RL. Site specific rates of mitochondrial genomes and the phylogeny of eutheria. BMC Evol Biol. 2007;7:8.

27. Drummond AJ, Suchard MA, Xie D, Rambaut A. Bayesian phylogenetics with BEAUti and the BEAST 1.7. Mol Biol Evol. 2012;29:1969-73.

28. Nguyen L-T, Schmidt HA, von Haeseler A, Minh BQ. IQ-TREE: a fast and effective stochastic algorithm for estimating maximum-likelihood phylogenies. Mol Biol Evol. 2015;32:268-74.

29. Rambaut A, Drummond AJ, Xie D, Baele G, Suchard MA. Posterior summarisation in Bayesian phylogenetics using Tracer 1.7. Syst Biol. 2018. doi: 10.1093/sysbio/syy032 .

30. Yu G, Smith DK, Zhu H, Guan Y, Lam TT-Y. ggtree : an r package for visualization and annotation of phylogenetic trees with their covariates and other associated data. Methods Ecol Evol. 2017;8:28-36.

31. Paradis E, Claude J, Strimmer K. APE: Analyses of Phylogenetics and Evolution in R language. Bioinformatics. 2004;20:289-90.

32. Matzke NJ. Probabilistic Historical Biogeography: New Models for Founder-Event Speciation, Imperfect Detection, and Fossils Allow Improved Accuracy and Model-Testing. 2013. 
33. Yu Y, Harris AJ, Blair C, He X. RASP (Reconstruct Ancestral State in Phylogenies): a tool for historical biogeography. Mol Phylogenet Evol. 2015;87:46-9.

34. Ronquist F. Dispersal-Vicariance Analysis: A New Approach to the Quantification of Historical Biogeography. Syst Biol. 1997;46:195-203.

35. Yu Y, Harris AJ, He X. S-DIVA (Statistical Dispersal-Vicariance Analysis): A tool for inferring biogeographic histories. Mol Phylogenet Evol. 2010;56:848-50.

36. Ree RH, Smith SA. Maximum likelihood inference of geographic range evolution by dispersal, local extinction, and cladogenesis. Syst Biol. 2008;57:4-14.

37. Landis MJ, Matzke NJ, Moore BR, Huelsenbeck JP. Bayesian analysis of biogeography when the number of areas is large. Syst Biol. 2013;62:789-804.

38. Matzke NJ. Model selection in historical biogeography reveals that founder-event speciation is a crucial process in Island Clades. Syst Biol. 2014;63:951-70.

39. Gregory-Wodzicki KM. Uplift history of the Central and Northern Andes: A review. Geol Soc Am Bull. 2000;112:1091-105.

40. Höhna S, Landis MJ, Heath TA, Boussau B, Lartillot N, Moore BR, et al. RevBayes: Bayesian Phylogenetic Inference Using Graphical Models and an Interactive Model-Specification Language. Syst Biol. 2016;65:726-36.

41. Höhna S, Heath TA, Boussau B, Landis MJ, Ronquist F, Huelsenbeck JP. Probabilistic graphical model representation in phylogenetics. Syst Biol. 2014;63:753-71.

42. Kass RE, Raftery AE. Bayes Factors. J Am Stat Assoc. 1995;90:773-95.

43. Xie W, Lewis PO, Fan Y, Kuo L, Chen M-H. Improving marginal likelihood estimation for Bayesian phylogenetic model selection. Syst Biol. 2011;60:150-60.

44. Lartillot N, Philippe H. Computing Bayes factors using thermodynamic integration. Syst Biol. 2006;55:195-207.

45. May MR, Höhna S, Moore BR. A Bayesian approach for detecting the impact of mass-extinction events on molecular phylogenies when rates of lineage diversification may vary. Methods Ecol Evol. 2016;7:947-59.

46. Höhna S. The time-dependent reconstructed evolutionary process with a key-role for mass-extinction events. J Theor Biol. 2015;380:321-31.

\section{Tables}




\section{Figures}

\section{Polythore Clade \\ Euthore Clade \\ Miocora Clade \\ Cora s.s. Clade \\ Chalcopteryx - Chalcothore Clade}

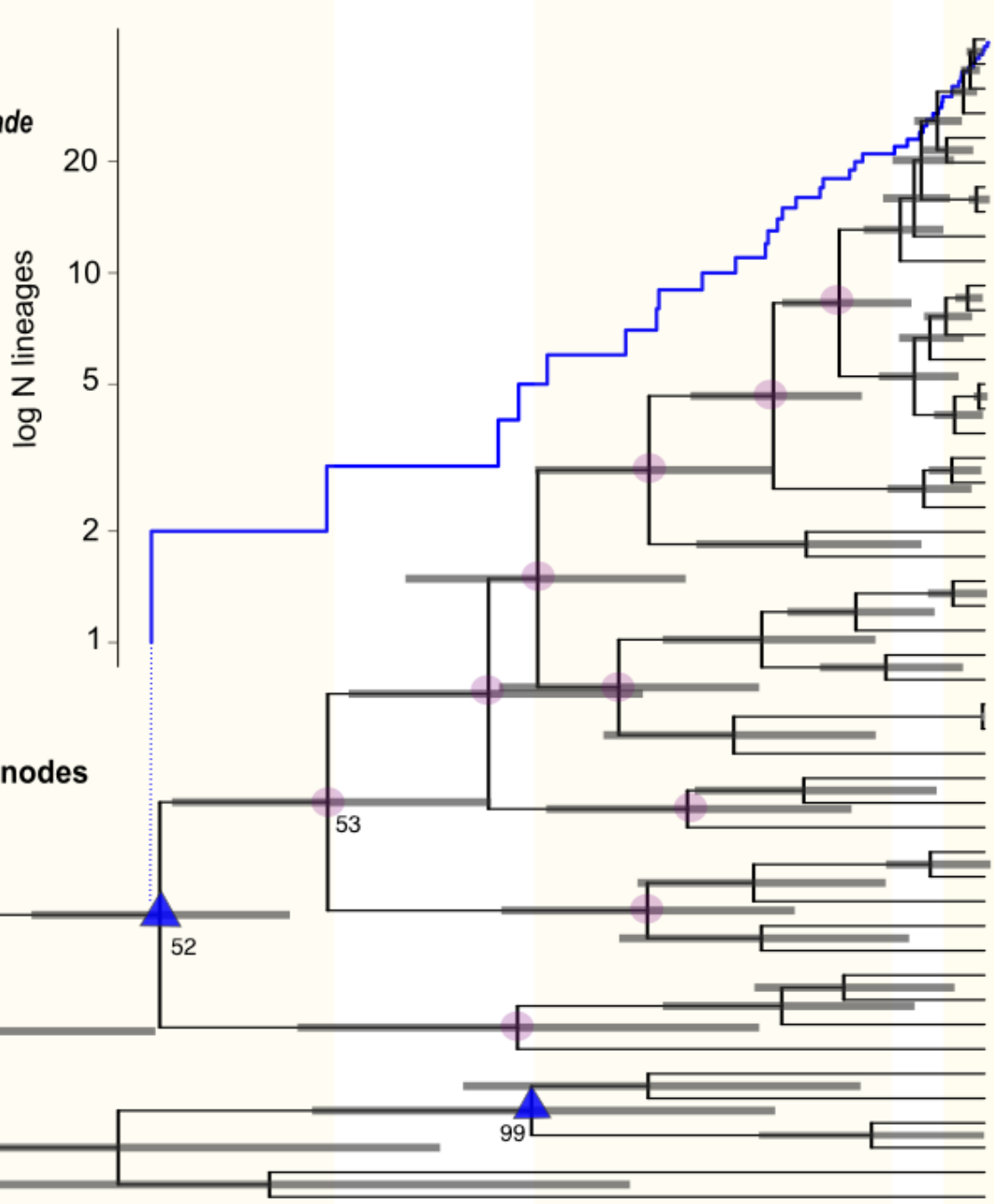

P. procera

P. concinna

P. sp. nov

$P$. concinna

$P$. sp. nov

P. procera

P. derivata

P. terminata

P. derivata

$P$. procera

P. manua

P. ornata

P. spaeteri

$P$. boliviana

$P$. victoria

P. picta

P.neopicta

P. gigantea

P. mutata

$P$. aurora

E. fas. plagiata

E. fassli

E. $s p$. nov.

E. fas. fastigiata

E. fas. fasciata

E. lugubris

E. klenei

M. peraltica

$M$. chirripa

$M$. aurea

C. cyane

C.xanthosoma

C. irene

C. verapax sp. nov.

C. inca

Cha. rutilans

Cha. scintillans

Cha. sp.

Ch. montgomeryi

\section{Outgroups}

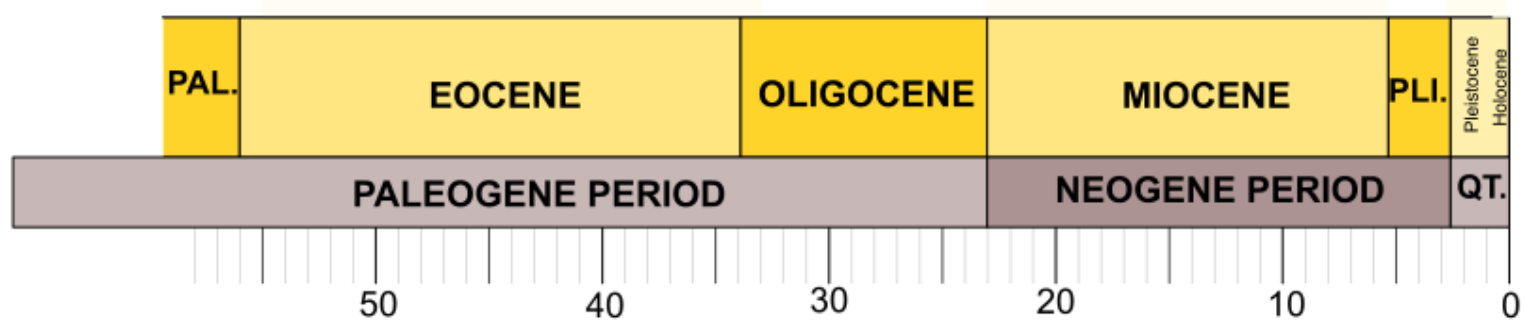

0 time (million years)

\section{Figure 1}

Bayesian time-calibrated best tree obtained in BEAST v1.8.4 with median node ages and $95 \%$ High Probability Density (HPD) intervals for each node. Fossil calibrated nodes are represented as blue triangles, while estimated nodes are represented as purple circles within the topology. All the major clades recovered previously by Sanchez-Herrera 13 are color coded at the end of all species names at the tips according to the legend, top-left. A Log-Lineages through time plot is displayed starting above node 52. 


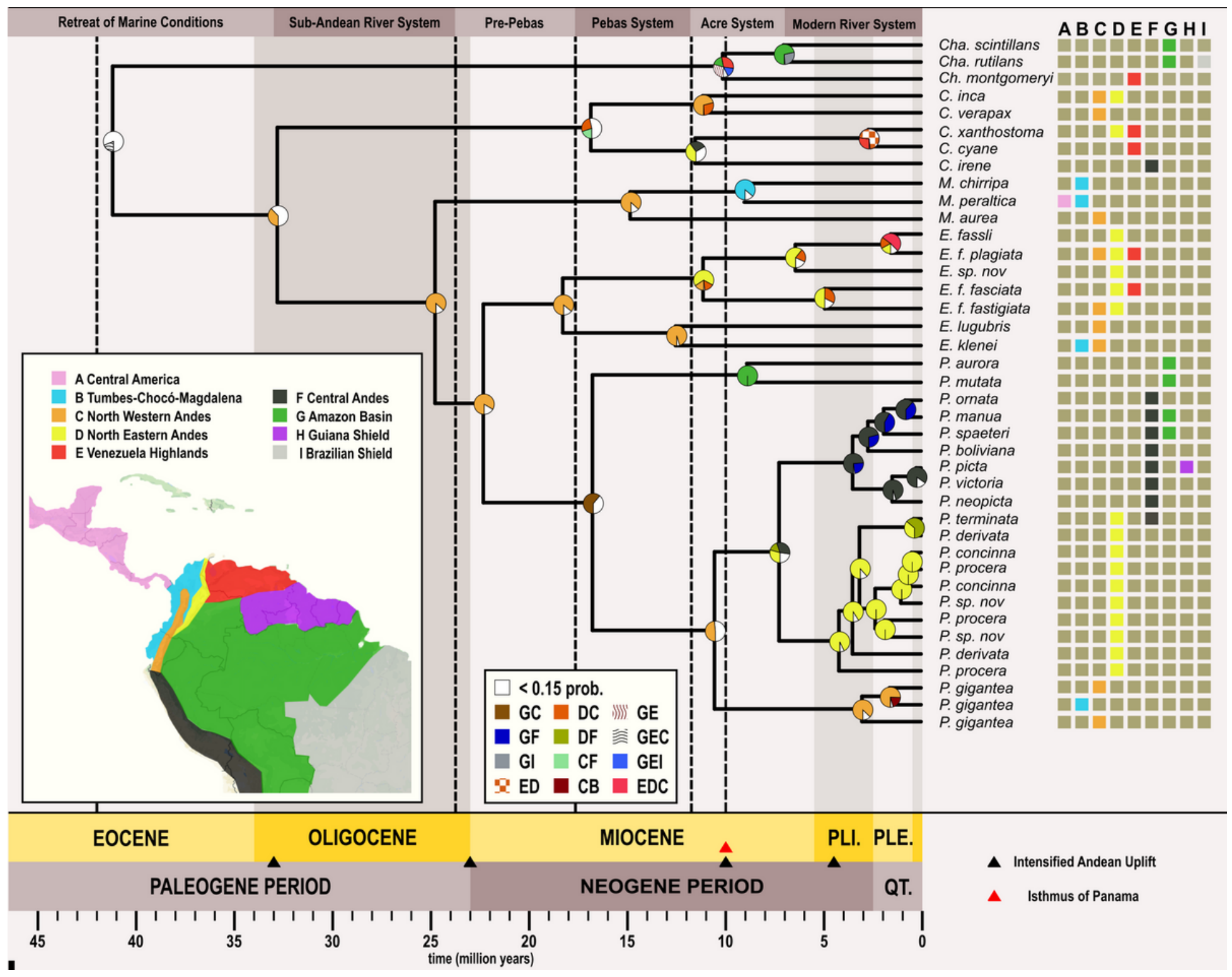

Figure 2

Time-Calibrated tree showing the ancestral area reconstruction of the S-DEC model implemented in RASP for the ANDES scenario. At the bottom-left there is a color-coded map showing the major biogeographical regions used within the analyses. To the right of all the tips of the tree there is a color-coded matrix representing the current distribution of all the taxa. All internal nodes display a probability pie chart of the reconstructed ancestral areas, which are color-coded in the middle-bottom legend. Above, there is a banner showing the major marine incursion events and below are small triangles showing the formation of the Isthmus of Panama (red) and Intensified Andean uplift (black). 
Diversification $\Lambda$ net $=\Lambda-\mu$

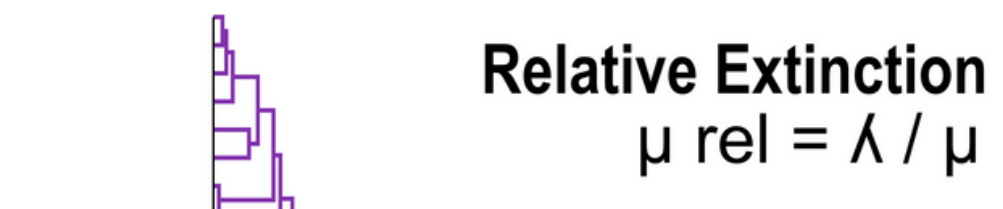

Polythore

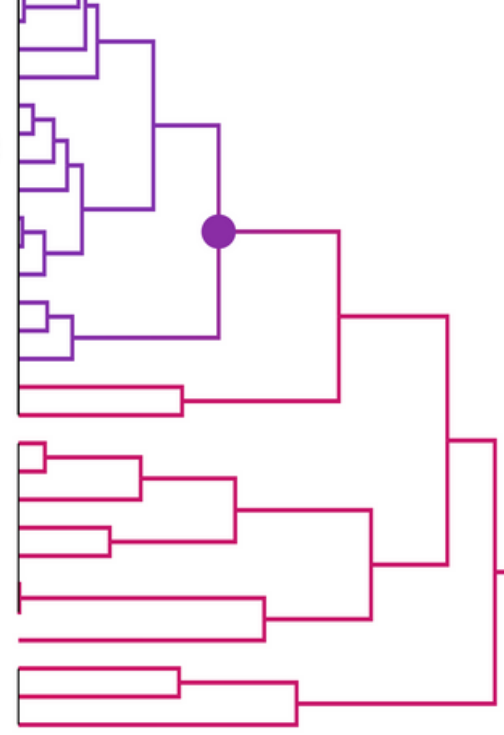

Miocora

Cora S.s

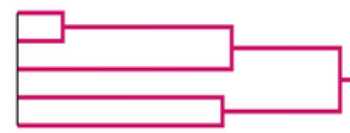

Chalcopteryx

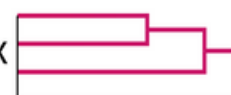

Figure 3

Diversification and Extinction rate shifts within the Polythoridae family obtained using the RevBayes Branch-Specific diversification model. To the left, the net diversification rate is represented, while to the right is the relative extinction rate.

\section{Supplementary Files}

This is a list of supplementary files associated with this preprint. Click to download.

- SupplementaryMaterial.docx

- Tables.docx 